\title{
Characterization of Extreme Storm Events Using a Numerical Model-Based Precipitation Maximization Procedure in the Feather, Yuba, and American River Watersheds in California ${ }^{\mathscr{O}}$
}

\author{
NORIAKI OHARA \\ Department of Civil and Architectural Engineering, University of Wyoming, Laramie, Wyoming \\ M. LEVENT KAVVAS \\ University of California, Davis, Davis, California \\ Michael L. Anderson And Z. Q. Chen \\ California Department of Water Resources, Sacramento, California \\ KEI ISHIDA \\ University of California, Davis, Davis, California
}

(Manuscript received 25 November 2015, in final form 14 February 2017)

\begin{abstract}
Improvements on nonhydrostatic atmospheric models such as MM5 in the last few decades have enhanced our understanding of the precipitation mechanism affected by topography and nonlinear dynamics of the atmosphere. This study addresses the use of such a regional atmospheric model to estimate physical maximum precipitation rates for the next generation of flood management strategies under evolving climate conditions. First, 48 significant historical storm events were selected based on the continuous reconstructed precipitation conditions on the Feather, Yuba, and American River watersheds in California. Then, the boundary conditions of the numerical atmospheric model were modified with the fully saturated atmospheric layers $(100 \%$ relative humidity) to generate the atmospheric conditions that maximize the precipitation over the three watersheds. Surprisingly, maximizing the atmospheric moisture supply at the model boundary does not always increase the precipitation in the watersheds of interest. A rain-shadow effect of the topography seemed to be intensified by the abundance of the atmospheric moisture in some cases. Consequently, although the linkage between the precipitable water in the atmosphere and the ground precipitation is generally proportional, the alignment of the topography and the wind field can modulate their relationship. Finally, a methodology to maximize the steady-state precipitation rate was discussed to characterize the conceptual continuous heavy storm event in the Feather, Yuba, and American River basins.
\end{abstract}

\section{Introduction}

Extreme storm events in Northern California are mainly driven by large weather systems called atmospheric rivers (ARs; Zhu and Newell 1998). This large system in the northeastern Pacific Ocean is often referred to as the "Pineapple Express" since the moisture

Supplemental information related to this paper is available at the Journals Online website: http://dx.doi.org/10.1175/ JHM-D-15-0232.s1.

Corresponding author e-mail: Noriaki Ohara, nohara1@uwyo.edu converges near the Hawaiian Islands (Weaver 1962; Dettinger 2004). In fact, the majority of major winter storms in Northern California were produced by ARs (Ralph et al. 2006; Dettinger et al. 2011; Neiman et al. 2011; Ralph and Dettinger 2012; Swain et al. 2015). ARs have been characterized using atmospheric models combined with various field measurements (e.g., Hughes et al. 2012; Neiman et al. 2013). Lavers and Villarini (2015) showed that ARs contribute about $20 \%-30 \%$ of the total precipitation in the western United States and western Europe based on reanalysis datasets. The modeling efforts have mostly focused on reproduction of the natural events to analyze historically significant storm events. 
In this study, however, the boundary conditions, which are usually prepared by synoptic-scale atmospheric products, were artificially modified to investigate the AR events without changing the model formulations and parameterizations. This numerical experiment might elucidate the precipitation-generating processes around Northern California by artificially removing the atmospheric variabilities such as moisture content variation and dynamic wind field. This untraditional numerical modeling practice was originally developed for estimation of the probable maximum precipitation (PMP) used for the engineering design of hydraulic structures, particularly for the emergency spillway of a dam (Ohara et al. 2011). A storm event, which produces a possible worst flood event for a specified watershed where the hydraulic structure is located, is called a "design storm" in the hydrologic engineering field. The design storm has been generated from the historical extreme storm event by a technique called moisture maximization (WMO 1973, 1986; Myers 1967; Myers and Zehr 1980). Basically, the traditional moisture maximization procedure magnifies the precipitable water in the atmospheric column based on the historical surface dewpoint temperature record. Then, the PMP can be computed using the proportionality between the precipitable water of the atmosphere and the ground precipitation. This philosophy of the traditional PMP estimation was simply introduced into the state-of-theart numerical weather model. The PMP estimates using a numerical atmospheric model were first introduced by Ohara et al. (2011) and expanded by Ishida et al. (2015a,b). The major advantages of this new approach are 1) fully physically based estimation of maximum precipitation, 2) no assumption of the proportionality between the precipitable water and the ground precipitation, and 3) explicit orographic effect consideration. The disadvantages of the numerical method are 1) it is computationally expensive and 2) the estimation relies on the accuracy of the numerical atmospheric model. Typically, a large number of simulations may be required to obtain the maximum precipitation estimate for the area of interest. The widespread use of computers and the improvements in numerical atmospheric modeling technology in recent years allow fairly accurate reconstruction of historical atmospheric conditions. Particularly on the U.S. West Coast, modeled historical storm events are quite realistic (e.g., Garvert et al. 2005; Kure et al. 2013). Typically, the variations of the model-estimated precipitation stayed within the variation of the observed values when compared to the corresponding ground observations in the watersheds and monthly distributions by Parameter-Elevation Regressions on

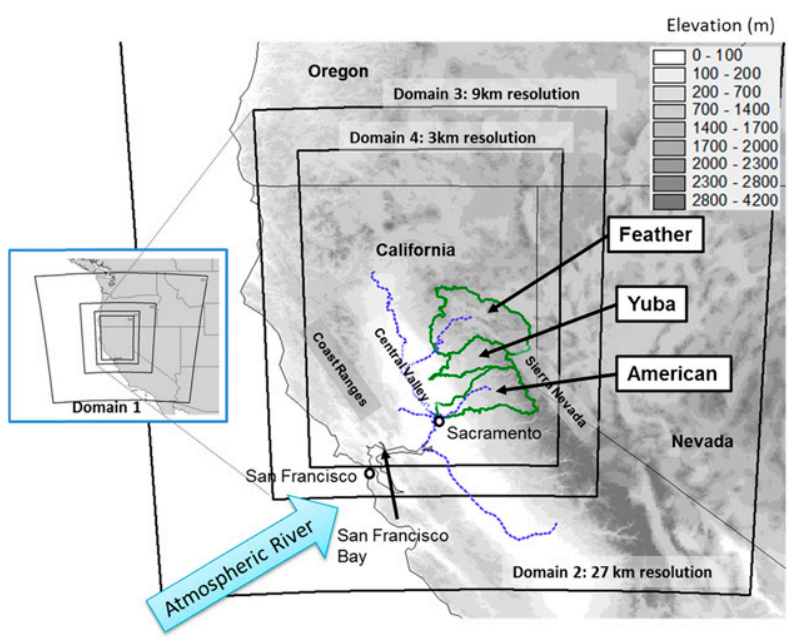

FIG. 1. Map of the study area: Feather, Yuba, and American River watersheds and nesting domains.

Independent Slopes Model (PRISM) data (Daly et al. 1994; Ohara et al. 2011; Jang et al. 2012; Jang and Kavvas 2015).

The true physical limit of precipitation, which is the conventional definition of PMP, should be unique under a static climate for a specific watershed. The PMP value may be altered by a global air temperature change that associates with the moisture-carrying capacity of the atmosphere. Kunkel et al. (2013) computed the global potential increases in atmospheric water vapor concentrations or precipitable water during the twentyfirst century, which may result in higher PMP. The numerical atmospheric models are capable of handling the nonstationary climate conditions, because the models can easily and explicitly incorporate the effect of climate change. The model-based maximum precipitation estimation is one of the most promising emerging techniques for engineering design practice under the changing climate conditions in the twenty-first century. However, this study will not explore the climate-induced change in the PMP estimates but will focus on the characterization of extreme precipitation under the historical climate conditions.

The study area is the Feather, Yuba, and American River watersheds, discussed in previous studies (Ishida et al. 2015a,b). The three watersheds are located on the western slope of the Sierra Nevada and produce the major floodwaters to the Sacramento-San Joaquin River delta and the Central Valley, as shown in Fig. 1. The Central Valley has suffered from frequent floods, particularly in the early twentieth century, before dam construction on the major tributaries. Even after completion of the Central Valley Project (CVP) and the State Water Project (SWP), occasional floods such as the 


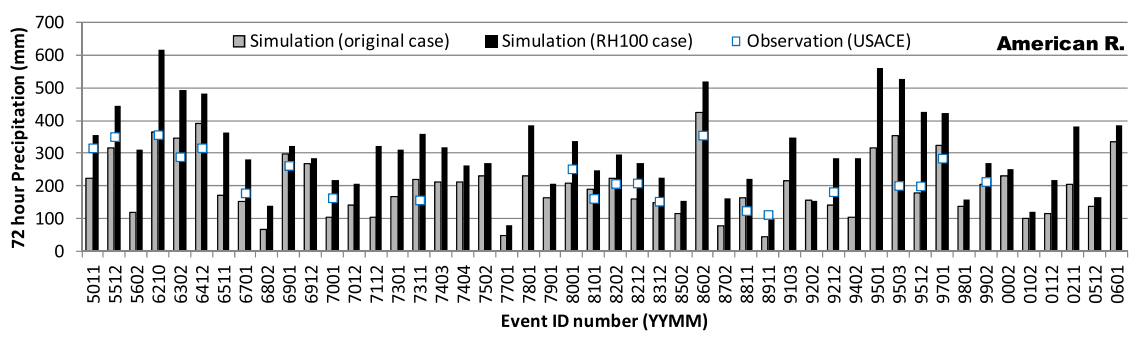

FIG. 2. Basin-average 72-h precipitation depths by the original simulation (gray bars), the moisture-maximized simulation (black bar), and the observations (squares) (USACE 2005) in the American River watershed. The event identification number indicates year and month (YYMM).

one in January 1997 had considerable economic and social impacts. Furthermore, there is a consensus that the anticipated climate change may increase the frequency of extreme storm events as well as amplify their magnitude (DWR 2006; Anderson et al. 2008; Dettinger 2011; IPCC 2013; Lavers et al. 2013). These extreme storm events in Northern California are mainly driven by the AR producing the majority of major winter storms in Northern California (e.g., Neiman et al. 2011). At the same time, the AR simplifies the flood-generating weather systems in this region to a manageable level of complexity. For instance, the incoming moisture flux from the west-side model boundary on the Pacific Ocean largely controls the storm system in Northern California.

In this study, the AR storms that can bring the largest precipitation in three selected watersheds, the American, Yuba, and Feather River basins, will be investigated using the model-based maximization methodology. This study basically hypothesized that the wind field orientation is as important as the precipitable water in the atmosphere because of the orographic effect of the steep terrain. First, the sensitivity analysis of the moisture input to the model domain was carried out using the historical 48 significant storm events. Then, a few special cases in which the orographic effect prevails over moisture maximization were analyzed in depth. Finally, the steady-state simulations were performed to eliminate the dynamic effect from the system. These model experiments will characterize the extreme flood events by analyzing the corresponding wind fields in the three watersheds in the Sierra Nevada.

\section{Methodology}

\section{a. Model configuration}

The fifth-generation Pennsylvania State UniversityNational Center for Atmospheric Research Mesoscale Model (MM5; Grell et al. 1994; NCAR 2005) was chosen to simulate a storm since this model was well configured and tested for the project area (Ohara et al. 2011; Ishida et al. 2015a,b). MM5 is an old version of the Weather Research and Forecasting (WRF) Model. However, both models solve the same equations, and the parameterization options in this work are still used in the contemporary WRF Model. Figure 1 shows the nesting domains of MM5 in this study. The Reisner graupel (Reisner 2) scheme (Reisner et al. 1998), the Medium-Range Forecast Model (MRF) planetary boundary layer (PBL) parameterization (Hong and Pan 1996), and the Kain-Fritsch, version 2 (Kain and Fritsch 1993), scheme were selected for the cloud microphysics, the PBL, and the cumulus parameterization options, respectively. The initial and boundary conditions were prepared based on the NCEP-NCAR reanalyses data (Kalnay et al. 1996). These model configurations were primarily optimized for the precipitation on the ground in the watersheds. The simulations will be validated in terms of event total precipitation in the relatively well-documented American River watershed. The model calibration and validation is only briefly mentioned in this article since it has been explained in detail in other publications (e.g., Ohara et al. 2011; Jang et al. 2012). This study focuses on the moisture maximization and steady-state characterization using 48 historical significant storm events since 1948.

Figure 2 shows the basin-average peak 72 -h precipitation depths for the 48 largest storm events since 1948 in the American River watershed. The basinaverage peak 72 -h precipitation was computed by the inverse-distance method using the 3-km-resolution MM5 outputs. The gray bars denote the simulated total precipitation depths for the events (original case), and the square dots are the corresponding estimated precipitation depths based on the observations (USACE 2005). The observed value was calculated with the Thiessen polygon method using the ground rain gauge records (USACE 2005). The 


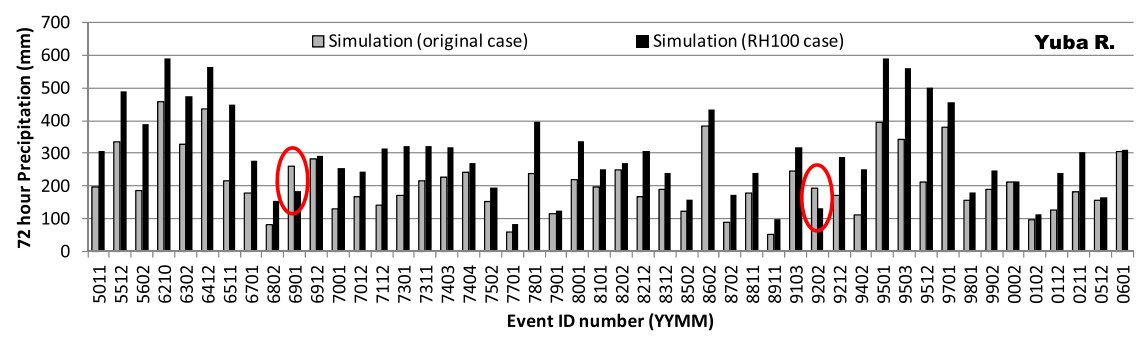

FIG. 3. Basin-average 72-h precipitation depths by the original simulation (gray bars) and the moisture-maximized simulation (black bar) in the Yuba River watershed. The event identification number indicates year and month (YYMM).

comparison of the gray bars and square dots shows that the modeled and observed precipitation depths are comparable. Although the U.S. Army Corps of Engineers (USACE) estimation of the 72-h precipitation depth may be regarded as a reference, its accuracy may vary with different events where fewer ground rain gauges were available. Furthermore, the basin-average peak 72 -h precipitation depths depend on the interpolation method used between the rain gauge stations. For example, investigators such as Roos (2003) and USACE (2005) disagreed on the estimates of the basin-average precipitation for the same event. Considering these factors, between computed and observed, the 72 -h precipitation depths are within the same range; the model simulations of these events represent reality fairly well. Further model validations can be found in Ohara et al. (2011), Jang et al. (2012), and Ishida et al. (2015a,b).

\section{b. Moisture maximization at the model boundary}

Using the numerical atmospheric model, the most straightforward method to maximize the atmospheric moisture without changing other state variables is to increase the relative humidity to $100 \%$ at all the model boundaries of the most outer domain at all atmospheric levels. The simulation periods for all storms were more than 7 days long, including the major storm to eliminate the influence of the initial condition, which was difficult to estimate accurately without data assimilation techniques. It was assumed that the effect of the initial value was decayed within the first 2-day period, and there are at least $48 \mathrm{~h}$ of a spinup period before the storm. When the initial condition effect was carefully eliminated, the simulation length did not affect the design storm magnitude because the maximum 72-h period was chosen from the moving basin total precipitation over the simulation period. The detailed procedure of the moisture maximization can be found in Ohara et al. (2011) and Ishida et al. (2015a,b).

Figure 2 shows the maximized moisture simulation results as black bars. The moisture supply has been maximized by setting relative humidity to $100 \%$ (RH100; Ohara et al. 2011). It can be seen that the 72-h precipitation depths of all the events were increased by this model boundary condition modification. However, it is notable that the amount of increase depends on the atmospheric conditions for these events. Also, these physical upper bounds estimated by the mesoscale model are less than the traditional PMP numbers: 800 (USWB 1961), 726 (Corrigan et al. 1999), and $752 \mathrm{~mm}$ (USACE 2001) in the American River watershed.

Figures 3 and 4 show the results of the same moisture maximization simulations for the Yuba and Feather watersheds. It is surprising that a few events (red circles) were diminished by the moisture maximization of the model boundary condition, although most of the events increased in precipitation. The 72-h precipitation depths of the January 1969 and December 1992 events drastically decreased in the Yuba and Feather watersheds as the moisture was increased at the model boundary. This indicated that the increase in the moisture supply from the Pacific Ocean may not always increase the ground precipitation in these watersheds.

These results obviously contradict the traditional moisture maximization concept for the development of PMP (Schreiner and Riedel 1978). For instance, this analysis suggests that the precipitation on the ground may not be proportional to the precipitable water in the atmosphere in California. In mathematical terms, this can be written as

$$
\frac{P_{\max }}{P_{\text {storm }}} \neq \frac{w_{\text {max }}}{w_{\text {storm }}},
$$

where $P$ is the ground precipitation, $w$ is the precipitable water in the atmosphere, and subscript "storm" denotes historical storm while subscript "max" denotes the maximized storm. These numerical results illustrate the limitation of the fundamental assumption in the traditional PMP procedure for use in a mountainous region like California. Clearly, the atmosphere is complex and nonlinear in many aspects. This study 


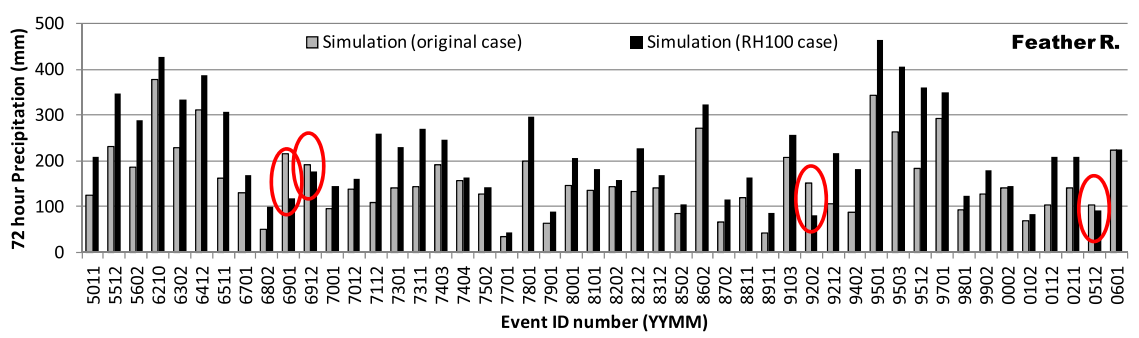

FIG. 4. Basin-average 72-h precipitation depths by the original simulation (gray bars) and the moisture-maximized simulation (black bar) in the Feather River watershed. The event identification number indicates year and month (YYMM). The moisture maximization reduced the precipitation yields of 4 cases out of 48 storm events.

will explore the causes of the ground precipitation reduction after moisture maximization using a numerical atmospheric model.

\section{Investigation on precipitation reduction by moisture increase}

The January 1969 storm event (ID 6901) that yielded a substantial precipitation reduction in the Feather River watershed due to moisture maximization over the Pacific Ocean (the left-hand-side boundary condition for moisture) is closely examined in this section. The numerical experiment results of the original (Orig) and moisture-maximized (RH100) precipitation are shown in Fig. 5. The area graph denotes basin-average hourly precipitation of the original case, and the line graph represents the moisturemaximized case (RH100). The first event peaks during 19-22 January were significantly reduced by the moisture maximization while the next rain/snowfall cluster during 25-27 January did not seem to be affected by the additional vapor. Even within a single event, the model boundary modification may irregularly influence the precipitation yield in a watershed in Sierra Nevada. This implies the complexity of the atmospheric system in California.

One of the possible reasons for the precipitation decrease by the moisture maximization may be the irregularity in the spatial distribution of the convective precipitation. It is conceivable that the location and intensity of convective precipitation have an effect on the precipitation during a typical storm event. The random convective precipitation production with respect to spatial location may be one of the factors in the reduction of precipitation after the moisture maximization. However, no sufficient evidence of the small-scale convective motion of the atmosphere was found in the simulation to explain the unexpected precipitation reduction over the entire Feather and Yuba River watersheds. The horizontal convergence of air and vapor due to the AR may be a more important factor influencing precipitation than the local convective rain cells over the Sierra Nevada watersheds.

\section{Rain-shadow effect}

As mentioned earlier, the extreme storm events over the study region are mainly brought by a much larger weather system known as the AR or Pineapple Express. Therefore, the regional moisture and wind fields associated with this system will be examined in this section. Figure 6 shows the computed precipitation field of the original case (Fig. 6, left) and the difference between the RH100 (moisture maximized) case and the original case (Fig. 6, right) in the model domain 4 during the January 1969 storm event (ID 6901). The precipitation field in Fig. 6 (left) maps the maximum 72-h precipitation at every computational cell. When this is compared to the topography map in Fig. 1, the high-precipitation nodes are mostly found in the highelevation regions. Therefore, the computed maximum 72-h precipitation is highly correlated with the geographical location of the watershed.

The map in Fig. 6 (right) shows the difference between the original case precipitation field (Orig) and the moisture-maximized precipitation field (RH100). This

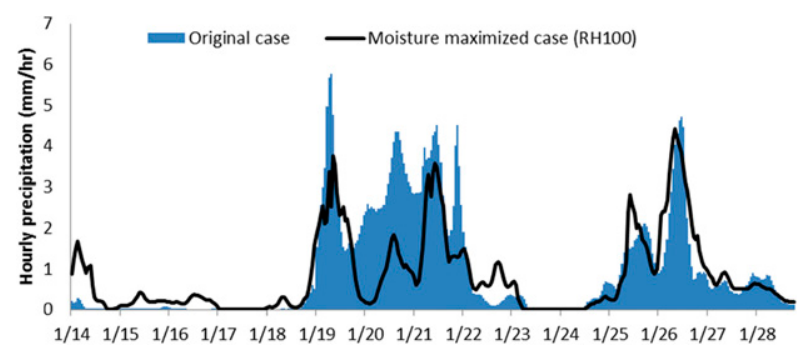

FIG. 5. Original and maximized basin-average precipitation at the Feather River watershed during the January 1969 storm event. The area graphs denote hourly precipitation of the original (historical) case, and the line graph is the moisture-maximized case (RH100). 


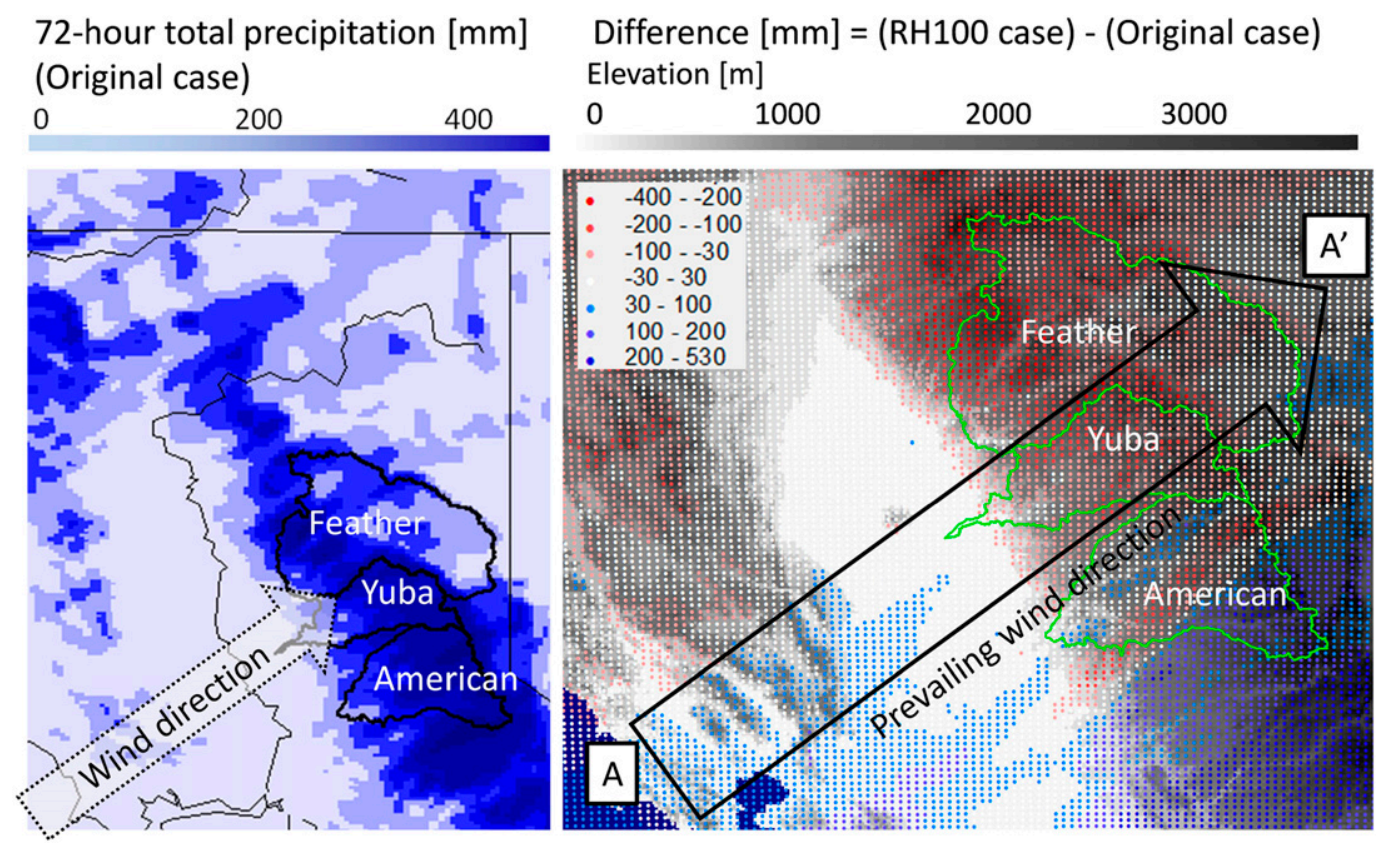

FIG. 6. (left) Event total precipitation field without the moisture maximization and (right) the difference field of the reconstructed precipitation of the January 1969 storm. The difference is defined as the moisture-maximized ground precipitation minus the original one.

difference map indicates that precipitation increases mostly in the southwest sector of the model domain 4 and in the Central Valley while the precipitation decreases around the west slope of the Sierra Nevada, where the Feather and Yuba River basins are situated. Figure 6 (right) suggested that the additional moisture possibly moved to the south despite the prevailing westsouthwest wind (near surface) and southwest wind (middle atmosphere, $500 \mathrm{hPa}$ ). However, any clear difference in hourly wind fields between the original and maximized cases was detected.

A possible hypothesis is a rain-shadow effect on the Coast Ranges. Considering the approximate prevailing wind direction at the middle atmosphere $(890 \mathrm{hPa})$ during the event depicted on the topography map, the terrestrial peaks in the Coast Ranges became wetter than in the original case after moisture maximization. These maps imply that the maximized moisture inflow from the Pacific Ocean may increase the rain-shadow effect along the wind path $A-A^{\prime}$. It is interesting that the increases were found on the leeward side of the Coast Ranges while the orographic precipitation typically takes place on the windward side. This indicates that the additional moisture mainly seems to extend the orographic precipitation area and run over the mountains rather than intensify the precipitation. The rain-shadow effect schematic in Fig. 7 partially explains the precipitation generation mechanism from the California coast to the Sierra Nevada. The moisture-maximized air from the Pacific Ocean may discharge precipitable water more effectively on the Coast Ranges, and in turn, this may result in less precipitation over the Sierra Nevada region than in the original case. The rain-shadow effect may also be able to explain why only the Yuba and Feather River watersheds experienced precipitation reduction after moisture maximization and not the American River watershed. The American River watershed (Fig. 1) is located along the wind path of the typical AR entering through San Francisco Bay. The
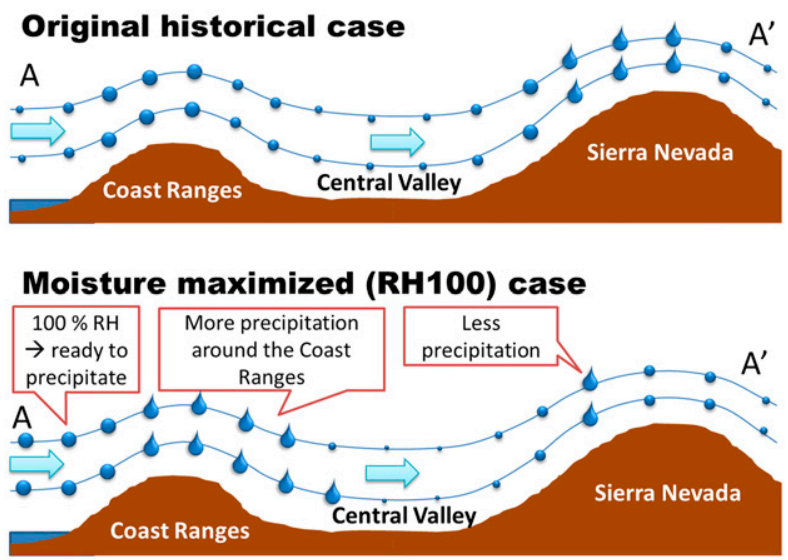

FIG. 7. Schematic description of the rain-shadow effect mechanism with consideration of atmospheric moisture maximization. 
Yuba and Feather River watersheds are not in the same wind path because of the Coast Ranges shadowing the precipitation. This analysis illustrates the importance of the wind field orientation relative to the Coast Ranges for the water yield in Sierra Nevada watersheds.

The precipitating process on the Sierra Nevada seemed much more complicated than a simple orographic effect from this analysis. The maximized moisture supply overwhelmed the precipitation generation in many cases while the rain-shadow effect overcame in a few cases. It was also reported by Hughes et al. (2012) and Neiman et al. (2013) that the near-surface wind along the Central Valley called "Sierra barrier jet" below the AR influenced this process as well. In fact, the moisture distribution in Fig. 10 in Ishida et al. (2015a) showed air moisture accumulation on the Central Valley, which is possibly due to the Sierra barrier jet. Moreover, since these processes are highly dynamic, it is difficult to characterize the optimum configurations for the physical upper bound of the precipitation.

\section{Analysis of wind direction using steady-state simulations}

The numerical weather experiments revealed the complicated atmospheric processes of the precipitation production in Northern California. As such, there is no guarantee that increases of the atmospheric moisture over the Pacific Ocean would magnify the precipitation over a target watershed in the Sierra Nevada. In this section, characterization of the wind directions and wind paths over the Coast Ranges that bring heavy precipitation to the watersheds in the Sierra Nevada is attempted.

As the fast-evolving wind field makes characterization difficult, this section will analyze the extreme storm events by means of steady-state atmospheric simulation using the regional atmospheric model with a constant boundary condition. It is a common engineering practice to reduce the degrees of freedom in the dynamics of a system in order to evaluate the worstcase scenario. Trial and error procedure for various static atmospheric boundary conditions can determine the atmospheric conditions that can bring the largest continuous precipitation rate to the three target watersheds. An example maximization of the steadystate atmospheric condition is shown in Fig. 8. The watershed-averaged precipitation reached a maximum soon after setting the steady-state boundary condition, although there were slight daily oscillations because of the radiation energy flux. Figure 8 suggests that the maximized precipitation intensity in the Feather River watershed was found to be $10.98 \mathrm{~mm} \mathrm{~h}^{-1}$ using the

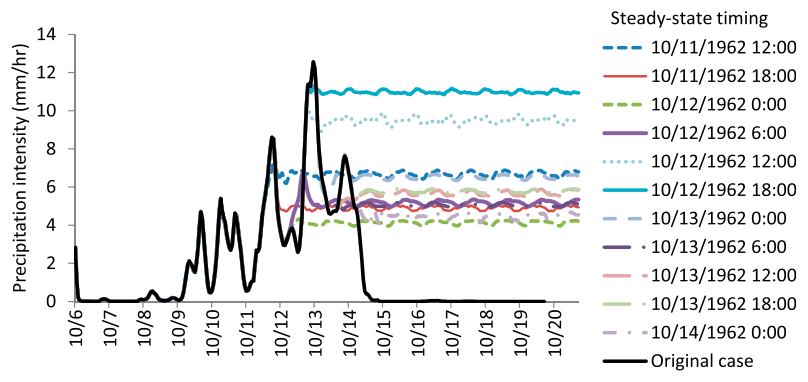

FIG. 8. Searching for the max continuous precipitation rate by changing the timing of the steady-state boundary condition (BC) using the October 1962 storm event. The BC at 1800 UTC 12 Oct 1962 was found to yield the largest steady-state precipitation rate over the Feather River watershed.

steady-state boundary condition at 1800 coordinated universal time (UTC) 12 October 1962. The same trialand-error procedure to find the maximum continuous precipitation rate for the other significant storm events was carried out.

Note that all simulations were also moisture maximized. Table 1 summarizes the top 10 largest steadystate precipitation events for the three watersheds. It was found that the October 1962 event yielded the maximum steady-state precipitation for the American and Feather River watersheds, while the March 1995 event was the largest for the Yuba River watershed. According to this analysis, the largest possible basinaverage and continuous precipitation rates were computed to be $10.98 \mathrm{~mm} \mathrm{~h}^{-1}$ for the Feather River watershed $\left(9334 \mathrm{~km}^{2}\right), 14.35 \mathrm{~mm} \mathrm{~h}^{-1}$ for the American River watershed $\left(4825 \mathrm{~km}^{2}\right)$, and $20.40 \mathrm{~mm} \mathrm{~h}^{-1}$ for the Yuba River watershed $\left(3483 \mathrm{~km}^{2}\right)$.

Figure 9 shows the atmospheric conditions of the October 1962 event that yielded maximum steady-state precipitation for the Feather and American River watersheds. The corresponding animation is available as supplemental material. Figure 9 (left) depicts the maximum steady-state ground precipitation rate and near-surface wind field at $10 \mathrm{~m}$ above the ground, while Fig. 9 (right) presents the vertical mean mixing ratio (potential precipitation) and wind speeds at two pressure levels in the troposphere $(500$ and $890 \mathrm{hPa})$. The prevailing wind direction is also shown in the north-based azimuth angle in Fig. 9 (shaded large arrow). These graphics indicate that when the wind directions in the middle atmosphere within the troposphere (Fig. 9, right) are aligned toward San Francisco Bay, precipitation in the target watersheds may be effectively maximized. It may also be inferred that the middle atmospheric wind may be more representative in the characterization of the rain-shadow effect than the near-surface wind. This in fact agreed with the orographic controlling layer $(\sim 1.5 \mathrm{~km}$ from the mean sea level), 
TABLE 1. Identified max precipitation intensity for Feather, Yuba, and American River watersheds by the steady-state simulations.

\begin{tabular}{|c|c|c|c|c|c|c|}
\hline \multirow[b]{2}{*}{ Rank } & \multicolumn{2}{|r|}{ Feather } & \multicolumn{2}{|r|}{ Yuba } & \multicolumn{2}{|r|}{ American } \\
\hline & Event ID & Precipitation $\left(\mathrm{mm} \mathrm{h}^{-1}\right)$ & Event ID & Precipitation $\left(\mathrm{mm} \mathrm{h}^{-1}\right)$ & Event ID & Precipitation $\left(\mathrm{mm} \mathrm{h}^{-1}\right)$ \\
\hline 1 & 6210 & 10.98 & 9503 & 20.40 & 6210 & 14.35 \\
\hline 2 & 9512 & 9.45 & 6412 & 18.48 & 6901 & 13.82 \\
\hline 3 & 9701 & 9.00 & 6210 & 14.02 & 7801 & 13.46 \\
\hline 4 & 9503 & 8.28 & 9701 & 13.04 & 6412 & 12.12 \\
\hline 5 & 9103 & 7.83 & 6302 & 12.94 & 8602 & 11.27 \\
\hline 6 & 6302 & 7.56 & 9512 & 12.84 & 9103 & 11.02 \\
\hline 7 & 6412 & 7.29 & 8602 & 9.74 & 9701 & 10.64 \\
\hline 8 & 8602 & 6.88 & 6511 & 9.41 & 6302 & 10.32 \\
\hline 9 & 6511 & 6.82 & 5512 & 8.09 & 9503 & 10.01 \\
\hline 10 & 5512 & 5.90 & 5602 & 7.72 & 9512 & 9.98 \\
\hline
\end{tabular}

which has the strongest correlation to the orographic precipitation in the Sierra Nevada (Neiman et al. 2013).

Figure 10 shows that the estimated maximum steadystate precipitation conditions for the Yuba River basin are based on the March 1995 event and the corresponding animation is available (supplemental material of this article). Since the Yuba River watershed is smaller than the other two watersheds, a narrower but more intense AR could deliver more water to the watershed. A broad AR seems to be required to achieve high basin-average precipitation over the American and Feather River watersheds, which are significantly larger than the Yuba River watershed. This implies that the watershed size may also influence the analysis results, and the maximization exercise seemed to normalize the moisture and orographic effects among three watersheds. This result is consistent with the well-known area-depth relationship (e.g., Chow 1964), although the mechanisms of this should be various and site specific. The middle wind direction of $217^{\circ}$ was found to be optimum for maximum water yield in the Yuba River watershed. The wind field appeared to have a common characteristic of the heavy precipitation events as the top five events shared a similar wind pattern (within $\pm 2^{\circ}$ of the mean prevailing wind direction). These conditions may allow recognition of potentially hazardous atmospheric conditions during daily weather prediction for flood control operation, as well as development of a model storm for possible engineering structures in the three target watersheds.

\section{Conclusions}

Moisture maximization using a numerical atmospheric model was examined for three California watersheds in the Sierra Nevada. Although additional atmospheric moisture increases the ground precipitation in the watersheds, the amplification rate was found to vary from event to event. More interestingly, the moisture maximization at the boundary of the model domain may reduce the water yield
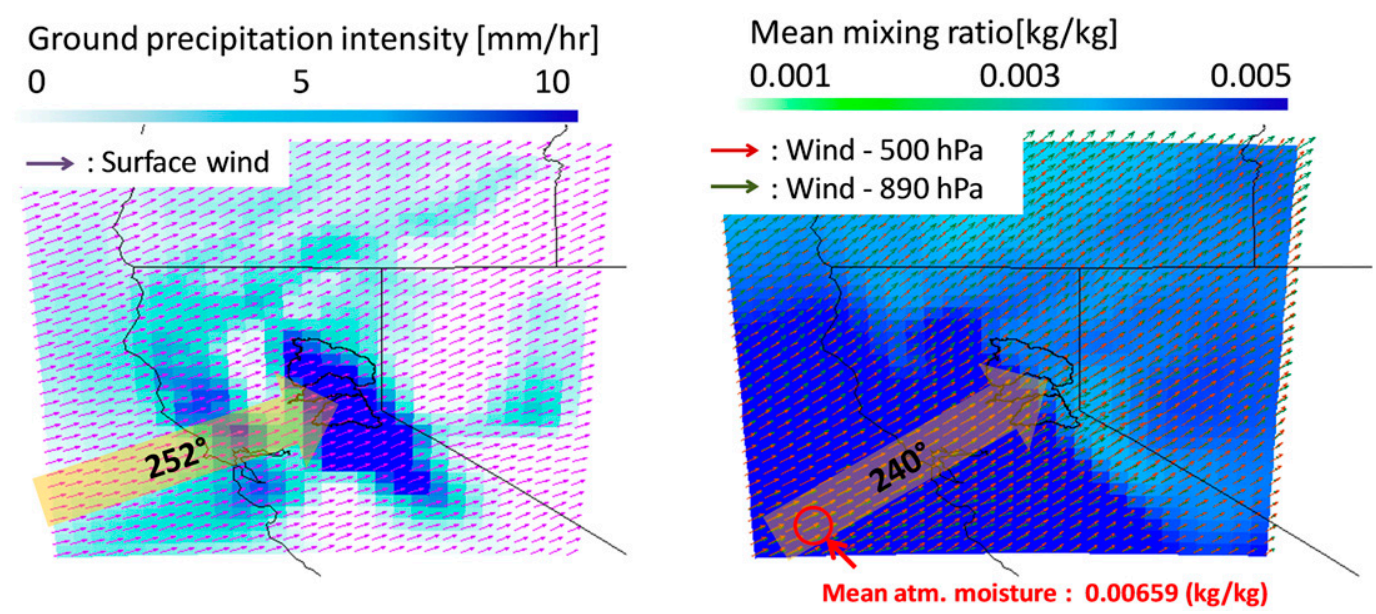

FIG. 9. Estimated max steady-state precipitation conditions for the Feather and American River watersheds based on the October 1962 event. The shaded arrows denote the wind directions (left) at near surface and (right) at middle altitude. 

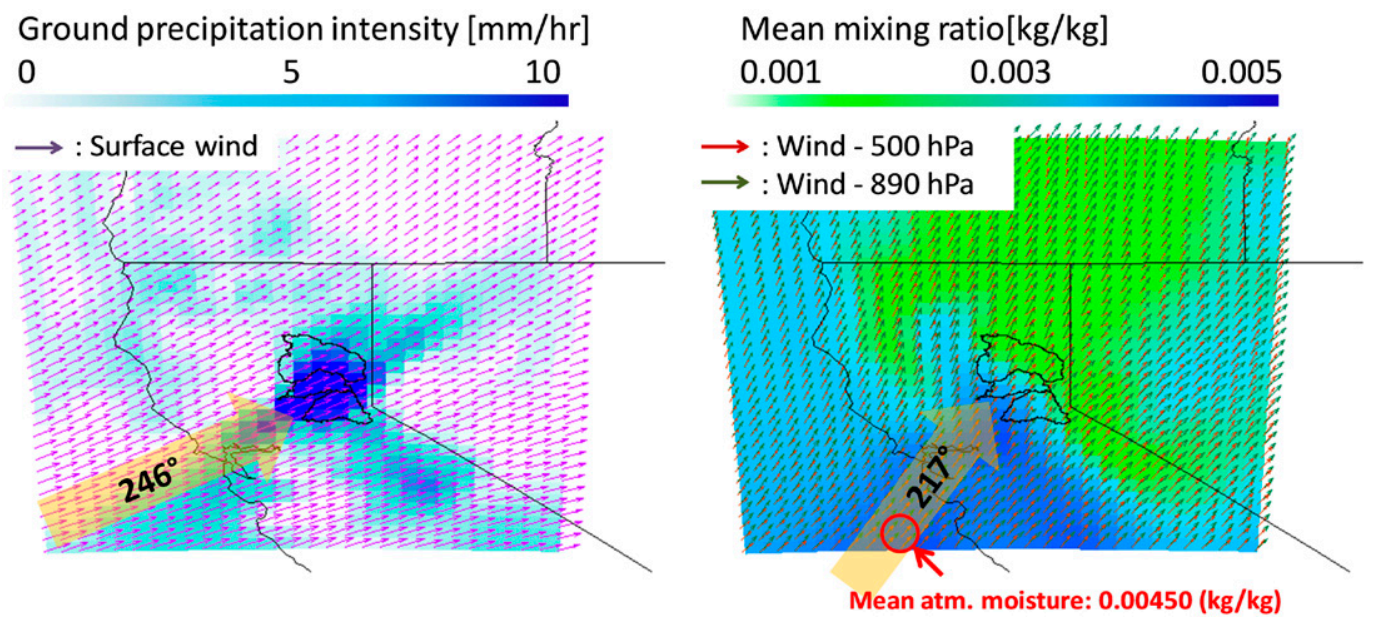

FIG. 10. Estimated max equilibrium precipitation conditions for Yuba River watershed based on the March 1995 event. The shaded arrows denote the wind directions (left) at near surface and (right) at middle altitude.

in some Sierra Nevada watersheds during a few specific events. This study focused on these rare and interesting cases to improve understanding of the precipitationgenerating system in California. Atmospheric moisture clearly has the potential to produce heavy precipitation on the ground over the Sierra Nevada watersheds, but the wind field also possesses a significant role in generating precipitation over the Sierra Nevada.

The storm events during which the ground precipitation was reduced over some of the three target Sierra Nevada watersheds by the moisture maximization over Pacific Ocean were analyzed by differentiating the original and the moisture-maximized precipitation distributions. Precipitation over the Sierra Nevada was decreased; it increased in the Coast Ranges and the west part of the Central Valley by the additional atmospheric moisture over the Pacific Ocean during the January 1969 storm event. This analysis suggested that the rain-shadow effect may be more pronounced when the atmosphere is nearly in saturation due to the moisture maximization.

To characterize the wind field that maximizes the precipitation over the three target watersheds, the unsteady conditions were removed from the storm system by setting static boundary conditions at a certain time for a certain storm event. The wind field that maximizes the static precipitation intensity was searched by a trialand-error procedure using the numerical atmospheric model simulations with various static boundary conditions during the historic severe storms over the three target watersheds. This numerical experiment verified the rain-shadow effect of the Coast Ranges on precipitation over the Sierra Nevada region, as the wind entering through San Francisco Bay maximized the static precipitation over the three target watersheds. It was found that the low-to-middle atmospheric wind fields (500- and 890-hPa levels) rather than the surface wind field seemed to be more suitable for characterizing the rain-shadow effect. This middle atmospheric layer corresponds well to the orographic control layer found by Neiman et al. (2013). The wind direction of $240^{\circ}$ in the large-scale October 1962 event was found to be optimum in creating maximum precipitation over the Feather and American River watersheds in Sierra Nevada, Northern California. However, the wind direction of $217^{\circ}$ in the smaller-scale October 1995 event brought more precipitation over the Yuba River watershed. The steady-state model experiment suggested that the physically possible continuous precipitation rates for Feather, American, and Yuba River watersheds were as high as $10.98,14.35$, and $20.40 \mathrm{~mm} \mathrm{~h}^{-1}$, respectively.

The results indicate that, in addition to the atmospheric moisture in the maximization of precipitation, wind direction and topographic features need to be considered. Also, watershed size may influence the precipitation rates when steady-state maximum precipitation is computed. These numerical experiments suggest that the basinaverage maximum precipitation is site specific. Understanding the atmospheric system over the target watershed is essential for obtaining realistic estimates of the basin-average maximum precipitation.

Acknowledgments. This study was financially supported by California Department of Water Resources Grant 3-84057-DWR 4600008548. While this support is gratefully acknowledged, it does not necessarily reflect the views of the funding agency. We also thank the editor, Dr. A.W. Wood, and four anonymous reviewers for valuable and insightful comments. 


\section{REFERENCES}

Anderson, J., F. Chung, M. Anderson, L. Brekke, D. Easton, M. Ejeta, R. Peterson, and R. Snyder, 2008: Progress on incorporating climate change into management of California's water resources. Climatic Change, 87, 91-108, doi:10.1007/ s10584-007-9353-1.

Chow, V. T., 1964: Handbook of Applied Hydrology. McGrawHill, 1468 pp.

Corrigan, P., D. D. Fenn, D. R. Kluck, and J. L. Vogel, 1999: Probable maximum precipitation for California. NOAA Hydrometeorological Rep. 59, 419 pp. [Available online at http:// www.nws.noaa.gov/oh/hdsc/PMP_documents/HMR59.pdf.]

Daly, C., R. P. Neilson, and D. L. Phillips, 1994: A statisticaltopographic model for mapping climatological precipitation over mountainous terrain. J. Appl. Meteor., 33, 140-158, doi:10.1175/1520-0450(1994)033<0140:ASTMFM > 2.0.CO;2.

Dettinger, M. D., 2004: Fifty-two years of "Pineapple-Express" storms across the west coast of North America. PIER Project Rep. CEC-500-2005-004, California Energy Commission, 20 pp. [Available online at http://www.energy.ca.gov/2005publications/ CEC-500-2005-004/CEC-500-2005-004.PDF.]

— , 2011: Climate change, atmospheric rivers, and floods in California-A multimodel analysis of storm frequency and magnitude changes. J. Amer. Water Resour. Assoc., 47, 514523, doi:10.1111/j.1752-1688.2011.00546.x.

—, F. M. Ralph, T. Das, P. J. Neiman, D. R. Cayan, 2011: Atmospheric rivers, floods, and the water resources of California. Water, 3, 455-478, doi:10.3390/w3020445.

DWR, 2006: Progress on incorporating climate change into management of California's water resources. Tech. Memo. Rep., California Department of Water Resources, 339 pp. [Available online at http://baydeltaoffice.water.ca.gov/climatechange.cfm.]

Garvert, M. F., B. A. Colle, and C. F. Mass, 2005: The 13-14 December 2001 IMPROVE-2 event. Part I: Synoptic and mesoscale evolution and comparison with a mesoscale model simulation. J. Atmos. Sci., 62, 3474-3492, doi:10.1175/JAS3549.1.

Grell, G. A., J. Dudhia, and D. R. Stauffer, 1994: A description of the Fifth generation Penn State/NCAR Mesoscale Model (MM5). NCAR Tech. Note NCAR/TN-398+STR, 121 pp., doi:10.5065/D60Z716B.

Hong, S.-Y., and H.-L. Pan, 1996: Nonlocal boundary layer vertical diffusion in a medium-range forecast model. Mon. Wea. Rev., 124, 2322-2339, doi:10.1175/1520-0493(1996)124<2322: NBLVDI $>2.0 . \mathrm{CO} ; 2$.

Hughes, M., P. J. Neiman, E. Sukovich, and M. Ralph, 2012: Representation of the Sierra barrier jet in 11 years of a highresolution dynamical reanalysis downscaling compared with long-term wind profiler observations. J. Geophys. Res., 117, D18116, doi:10.1029/2012JD017869.

IPCC, 2013: Climate Change 2013: The Physical Science Basis. Cambridge University Press, 1535 pp., doi:10.1017/ CBO9781107415324.

Ishida, K., M. L. Kavvas, S. Jang, Z. Q. Chen, N. Ohara, and M. L. Anderson, 2015a: Physically based estimation of maximum precipitation over three watersheds in Northern California: Relative humidity maximization method. J. Hydrol. Eng., 20, 04015014, doi:10.1061/(ASCE)HE.1943-5584.0001175.

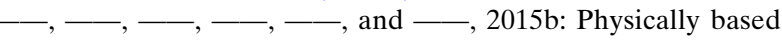
estimation of maximum precipitation over three watersheds in Northern California: Atmospheric boundary condition shifting. J. Hydrol. Eng., 20, 04014052, doi:10.1061/ (ASCE)HE.1943-5584.0001026.
Jang, S., and Kavvas, M., 2015: Downscaling global climate simulations to regional scales: Statistical downscaling versus dynamical downscaling. J. Hydrol. Eng., 20, doi:10.1061/ (ASCE)HE.1943-5584.0000939.

_ S. Kure, N. Ohara, M. L. Kavvas, G. Matanga, and K. Nelson, 2012: Regional climate change of atmospheric components in Northern California by dynamic downscaling. World Environmental and Water Resources Congress 2012, Albuquerque, NM, American Society of Civil Engineers, doi:10.1061/ 9780784412312.195.

Kain, J. S., and J. M. Fritsch, 1993: Convective parameterization for mesoscale models: The Kain-Fritsch scheme. The Representation of Cumulus Convection in Numerical Models, Meteor. Monogr., No. 46, Amer. Meteor. Soc., 165-170, doi:10.1007/ 978-1-935704-13-3_16.

Kalnay, E., and Coauthors, 1996: The NCEP/NCAR 40-Year Reanalysis Project. Bull. Amer. Meteor. Soc., 77, 437-471, doi:10.1175/1520-0477(1996)077<0437:TNYRP>2.0.CO;2.

Kunkel, K. E., T. R. Karl, D. R. Easterling, K. Redmond, J. Young, X. Yin, and P. Hennon, 2013: Probable maximum precipitation and climate change. Geophys. Res. Lett., 40, 14021408, doi:10.1002/grl.50334.

Kure, S., S. Jang, N. Ohara, M. L. Kavvas, and Z. Q. Chen, 2013: WEHY-HCM for modeling interactive atmospheric-hydrologic processes at watershed scale. II: Model application to ungauged and sparsely gauged watersheds. J. Hydrol. Eng., 18, 1272-1281, doi:10.1061/(ASCE)HE.1943-5584.0000701.

Lavers, D. A., and G. Villarini, 2015: The contribution of atmospheric rivers to precipitation in Europe and the United States. J. Hydrol., 522, 382-390, doi:10.1016/j.jhydrol.2014.12.010.

_ R. P. Allan, G. Villarini, B. Lloyd-Hughes, D. J. Brayshaw, and A. J. Wade, 2013: Future changes in atmospheric rivers and their implications for winter flooding in Britain. Environ. Res. Lett., 8, 034010, doi:10.1088/1748-9326/8/3/034010.

Myers, V. A., 1967: Estimation of extreme precipitation for spillway design floods. Tech. Memo. WBTM HYDRO-5, U.S. Weather Bureau, 29 pp. [Available online at http://www.nws. noaa.gov/oh/hdsc/Technical_memoranda/TM5.pdf.]

__ , and R. M. Zehr, 1980: A methodology for point-to-area rainfall frequency ratios. NOAA Tech. Rep. NWS 24, 176 pp. [Available online at http://www.nws.noaa.gov/oh/ hdsc/Technical_reports/TR24.pdf.]

NCAR, 2005: PSU/NCAR Mesoscale Modeling System tutorial class notes and user's guide: MM5 Modeling System version 3. Accessed 21 March 2017. [Available online at http://www2. mmm.ucar.edu/mm5/documents/tutorial-v3-notes.html.]

Neiman, P. J., L. J. Schick, F. M. Ralph, M. Hughes, and G. A. Wick, 2011: Flooding in western Washington: The connection to atmospheric rivers. J. Hydrometeor., 12, 1337-1358, doi:10.1175/2011JHM1358.1.

_- M. Hughes, B. J. Moore, F. M. Ralph, and E. M. Sukovich, 2013: Sierra barrier jets, atmospheric rivers, and precipitation characteristics in Northern California: A composite perspective based on a network of wind profilers. Mon. Wea. Rev., 141, 4211-4233, doi:10.1175/MWR-D-13-00112.1.

Ohara, N., M. L. Kavvas, S. Kure, Z. Q. Chen, S. Jang, and E. Tan, 2011: Physically based estimation of maximum precipitation over American River watershed, California. J. Hydrol. Eng., 16, 351-361, doi:10.1061/(ASCE)HE.1943-5584.0000324.

Ralph, F. M., and M. D. Dettinger, 2012: Historical and national perspectives on extreme West Coast precipitation associated with atmospheric rivers during December 2010. Bull. Amer. Meteor. Soc., 93, 783-790, doi:10.1175/BAMS-D-11-00188.1. 
P. J. Neiman, G. A. Wick, S. I. Gutman, M. D. Dettinger, D. R. Cayan, and A. B. White, 2006: Flooding on California's Russian River: Role of atmospheric rivers. Geophys. Res. Lett., 33, L13801, doi:10.1029/2006GL026689.

Reisner, J., R. J. Rasmussen, and R. T. Bruintjes, 1998: Explicit forecasting of supercooled liquid water in winter storms using the MM5 mesoscale model. Quart. J. Roy. Meteor. Soc., 124 1071-1107, doi:10.1002/qj.49712454804.

Roos, M., 2003: Extreme precipitation in the American River basin. California Extreme Precipitation Symposium, Davis, CA, American River Watershed Institute, 7 pp. [Available online at http://cepsym.org/Sympro2003/Roos.pdf.]

Schreiner, L. C., and J. T. Riedel, 1978: Probable maximum precipitation estimates, United States east of the 105th meridian. NOAA Hydrometeorological Rep. 51,100 pp. [Available online at http://www.nws.noaa.gov/oh/hdsc/PMP_documents/HMR51.pdf.]

Swain, D. L., B. Lebassi-Habtezion, and N. S. Diffenbaugh, 2015: Evaluation of nonhydrostatic simulations of northeast Pacific atmospheric rivers and comparison to in situ observations. Mon. Wea. Rev., 143, 3556-3569, doi:10.1175/MWR-D-15-0079.1.

USACE, 2001: American River basin, California, Folsom Dam and Lake, revised PMF study. U.S. Army Corps of Engineers, 100 pp.
- 2005: Stochastic modeling of extreme floods on the American River at Folsom Dam: Flood-frequency curve extension. Research Doc. 48, U.S. Army Corps of Engineers, 46 pp. [Available online at http://www.hec.usace.army.mil/publications/ ResearchDocuments/RD-48.pdf.]

USWB, 1961: Interim report: Probable maximum precipitation in California. U.S. Weather Bureau Hydrometeorological Rep. 36, 226 pp. [Available online at http://www.nws.noaa.gov/oh/ hdsc/PMP_documents/HMR36.pdf.]

Weaver, R. L., 1962: Meteorology of hydrologically critical storms in California. U.S. Weather Bureau Hydrometeorological Report 37, 227 pp. [Available online at http://www.nws.noaa. gov/oh/hdsc/PMP_documents/HMR37.pdf.]

World Meteorological Organization (WMO), 1973: Manual for estimation of probable maximum precipitation. Operation Hydrology Rep. 1, WMO-332, 190 pp.

, 1986: Manual for estimation of probable maximum precipitation. 2nd ed. Operation Hydrology Rep. 1, WMO-332, $269 \mathrm{pp}$.

Zhu, Y., and R. E. Newell, 1998: A proposed algorithm for moisture fluxes from atmospheric rivers. Mon. Wea. Rev., 126, 725-735, doi:10.1175/1520-0493(1998)126<0725:APAFMF>2.0.CO;2. 